Article

\title{
Is Preterm Birth a Risk Factor for Subsequent Autism Spectrum Disorder and Attention Deficit Hyperactivity Disorder in Children with Febrile Seizure?-A Retrospective Study
}

\author{
Chien-Heng Lin ${ }^{1,2} \mathbb{D}$, Wei-De Lin ${ }^{3}$, I-Ching Chou ${ }^{4}$, Inn-Chi Lee ${ }^{5}$ and Syuan-Yu Hong ${ }^{4,6,7, *}$ \\ 1 Division of Pediatrics Pulmonology, China Medical University Children's Hospital, Taichung 404327, Taiwan; \\ lch227@ms39.hinet.net \\ 2 Department of Biomedical Imaging and Radiological Science, College of Medicine, China Medical University, \\ Taichung 404327, Taiwan \\ 3 Department of Medical Research, China Medical University Hospital, Taichung 404327, Taiwan; \\ weide@mail.cmuh.org.tw \\ 4 Division of Pediatrics Neurology, China Medical University Children's Hospital, Taichung 404327, Taiwan; \\ iching@mail.cmu.edu.tw \\ 5 Department of Pediatrics, Chung Shan Medical University Hospital and Institute of Medicine, \\ School of Medicine, Chung Shan Medical University, Taichung 402306, Taiwan; y610@mercury.csmu.edu.tw \\ 6 Department of Medicine, School of Medicine, China Medical University, Taichung 404328, Taiwan \\ 7 Institute of Biomedicine, School of Medicine, China Medical University, Taichung 404328, Taiwan \\ * Correspondence: D28320@mail.cmuh.org.tw
}

check for

updates

Citation: Lin, C.-H.; Lin, W.-D.; Chou, I.-C.; Lee, I.-C.; Hong, S.-Y. Is Preterm Birth a Risk Factor for Subsequent Autism Spectrum Disorder and Attention Deficit Hyperactivity Disorder in Children with Febrile Seizure?-A

Retrospective Study. Life 2021, 11, 854. https://doi.org/10.3390/life11080854

Academic Editor: Michel Simonneau

Received: 5 July 2021

Accepted: 18 August 2021

Published: 20 August 2021

Publisher's Note: MDPI stays neutral with regard to jurisdictional claims in published maps and institutional affiliations.

Copyright: (c) 2021 by the authors. Licensee MDPI, Basel, Switzerland. This article is an open access article distributed under the terms and conditions of the Creative Commons Attribution (CC BY) license (https:// creativecommons.org/licenses/by/ $4.0 /)$.

\begin{abstract}
Febrile seizure (FS) is the most prevalent childhood seizure; it is significantly related to subsequent epilepsy and has possible links to childhood neurodevelopmental disorders. Separately, premature births are believed to increase the risk of attention deficit hyperactivity disorder (ADHD) and autism spectrum disorder (ASD). Therefore, this study investigated whether preterm birth is a risk factor for subsequent epilepsy, ASD, and ADHD in children with FS. We retrospectively collected data for children aged < 5 years with FS from 1 January 2005, to 31 December 2013. We divided these children into two groups - the premature birth group and the full-term group —and compared their incidence rates of epilepsy, ASD and ADHD. The data of 426 patients with history of febrile convulsion were retrospectively collected. The premature birth group (FS+/preterm + ) had 108 patients and the full-term group $(\mathrm{FS}+/$ preterm - ) had 318 patients. The overall epilepsy risk in the FS+/preterm+ group was higher than in the FS+/preterm - group (odds ratio [OR], 2.52; $95 \%$ confidence interval $[\mathrm{CI}], 1.14-5.58 ; p=0.02)$. The overall risk of ADHD in the FS+/preterm+ group was higher than that in the FS+/preterm- group (OR, 6.41; 95\% CI, 3.39-12.09; $p=0.0001)$. In addition, children with FS+/preterm+ had 16.9 times (95\% CI, 4.79-59.7; $p=0.0001$ ) higher odds of having ASD compared with those with FS+/preterm-. Preterm birth may be a risk factor for subsequent epilepsy, ASD and ADHD in children with FS.
\end{abstract}

Keywords: epilepsy; preterm; attention deficit hyperactivity disorder; autism spectrum disorder; neurodevelopmental disorders

\section{Introduction}

Autism spectrum disorder (ASD) and attention deficit hyperactivity disorder (ADHD) are two common neurodevelopmental disorders (NDDs) in children. ASD, which commonly manifests in the first years of life, is a disease with multifactorial etiology and typically manifests as social and communication impairments as well as stereotyped behaviors, whereas ADHD is characterized by inattention, hyperactivity and impulsivity. These disorders are thought to have a strong heritable component and identified risk factors include extremes of maternal or parental age, mothers with chemical intolerances, low socioeconomic status, prenatal exposure to smoking and alcohol and epilepsy [1-7]. 
Febrile seizure (FS), which has an onset age mostly between 14 and 18 months, is the most common childhood seizure, affecting $2-5 \%$ of children aged $<5$ years [8]. Although FS is an inherently benign process, it can recur in approximately $30 \%$ of cases, $2 \%$ of which may develop epilepsy [9]. Certain mental and neurodevelopmental consequences of FS have been identified, particularly ASD and ADHD [10-13]. Furthermore, some authors have reported that there is a strong association between epilepsy, FS and subsequent development of ADHD, especially in areas with high levels of urbanization [10,13]. Preterm birth is a major cause of death worldwide and can lead to major health problems. In Taiwan, approximately 200,000 infants are born annually, and the preterm birth rate is estimated to be $8-10 \%$. Infants born prematurely are at risk of major and minor defects, such as cerebral palsy, cognitive and speech delays, motor and visual deficits, psychosocial and behavioral disorders and dysfunction at school [14,15]. Therefore, studies have mentioned preterm birth as a risk factor for subsequent ADHD, especially in girls [15,16].

In this small, but clinically significant study, based on the abovementioned considerations, we sought to examine whether preterm birth acts as a prognostic factor for subsequent neurodevelopmental sequelae in children with FS. Our hypothesis was that preterm birth is a risk factor for not only epilepsy but also subsequent ASD and ADHD in children with FS.

\section{Methods and Approach}

\section{Patient Population}

The study protocol was approved by the Ethics Review Board of the China Medical University Ethics Committee (CMUH108-REC1-023). In this retrospective study, we collected data from children aged 0 -5 years who were born preterm and full-term and had been diagnosed with FS between 1 January 2005 and 31 December 2013. All subjects in the study (FS+/preterm+ and FS+/preterm-), were born in the China Medical University Children's Hospital and its three branches and their birth medical records were complete and detailed. Preterm birth in the present study was defined as any birth before 37 completed weeks of gestation. The diagnosis of FS was made by child neurologists in accordance with the following generally accepted criteria: (1) convulsions associated with an elevated temperature greater than $38^{\circ} \mathrm{C}$; (2) child aged older than 6 months and younger than 5 years; (3) absence of central nervous system infection or inflammation; (4) absence of acute systemic metabolic abnormality that may produce convulsions; and (5) no history of afebrile seizures [4].

All patients included in the study were followed up until the end of follow-up (31 December 2017). We followed up patients by reviewing their medical records and contacting their families via telephone or e-mail quarterly since the beginning of 2014, to investigate whether a first diagnosis of epilepsy, ASD, or ADHD after FS was confirmed. Since we included patients who were sure to be contacted, there were three lost cases in the follow-up (Figure 1).

Subsequently, we comprehensively reviewed the respective medical records toward the end of 2017. The exclusion criteria for study participants were as followings: those individuals who had died during follow-up, those that had been diagnosed with neoplasms, had undergone organ transplantation, or had any serious disease affecting the immune system (e.g., systemic lupus erythematosus or aplastic anemia) before or after FS. The children enrolled in the study were relatively healthy; that is, they had no epilepsy or neurological, metabolic, autoimmune, or any known congenital disorders before the onset of FS. The final study population comprised 108 patients (FS+/preterm+).

In addition, each patient in the FS+/preterm+ cohort was 1:3 propensity matched by age, sex, index year, urbanization to form a control group of 318 full-term children with FS (FS+/preterm-). Epilepsy was defined as two unprovoked seizures more than $24 \mathrm{~h}$ apart as diagnosed by a pediatric neurologist. Patients who met the relevant diagnostic criteria in the Fourth and Fifth Editions of the Diagnostic and Statistical Manual of Mental Disorders (DSM-4, DSM-5) were diagnosed with ASD and ADHD and their diagnoses were made by 
a pediatric psychiatrist or pediatric neurologist in an inpatient or outpatient setting in the China Medical University Children's Hospital between 1 January 2005 and December 31, 2017. Confounding factors were sex, gestational age, birth body weight, first FS duration and onset age, brain condition within 6 months of age and number of FSs (Table 1).

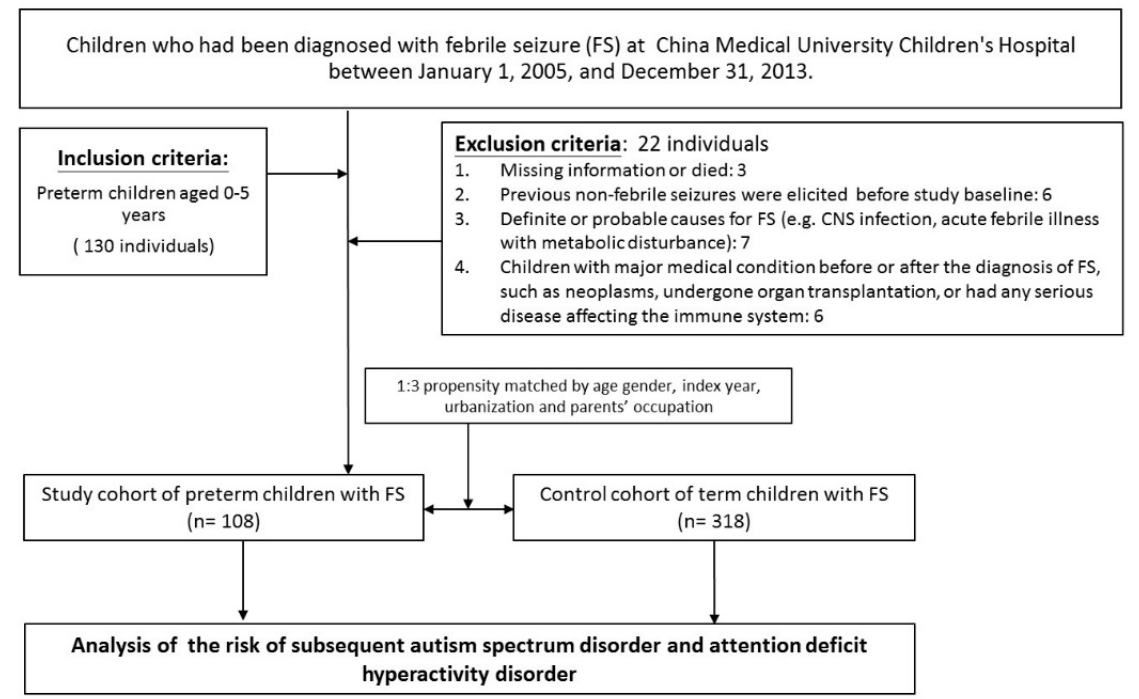

Figure 1. Study population and flowchart.

Table 1. Demographic and Clinical Characteristics of Preterm Children with Febrile Seizure (FS) and a Comparison with Full-Term Children with FS.

\begin{tabular}{|c|c|c|c|}
\hline \multirow{2}{*}{ Demographic and Clinical Characteristics } & \multicolumn{2}{|c|}{ Group } & \multirow[b]{2}{*}{$p$} \\
\hline & FS+/Preterm+ $(n=108)$ & FS $+/$ Preterm $-(n=318)$ & \\
\hline Mean 1st FS onset age (yrs) (SD) * & $2.30(1.14)$ & $2.19(1.10)$ & 0.62 \\
\hline Gender $(\%)$ & & & 0.99 \\
\hline Male & $72(66.7)$ & $212(66.7)$ & \\
\hline Female & $36(33.3)$ & $106(33.3)$ & \\
\hline GA (mean) $(\mathrm{SD})$ * & $29.9(6.00)$ & $38.4(1.07)$ & $<0.001$ \\
\hline $\mathrm{BBW}(\mathrm{gm})(\mathrm{SD})$ * & $1420(591)$ & $3053(395)$ & $<0.001$ \\
\hline Stratified by age (yrs) (\%) & & & 0.86 \\
\hline $0-1$ & $30(27.8)$ & $93(29.3)$ & \\
\hline $1-5$ & $78(72.2)$ & $225(70.7)$ & \\
\hline Mean 1st FS duration (mins) (SD) * & $8.69(10.05)$ & $5.81(5.58)$ & 0.03 \\
\hline No. of FS (SD) & $1.44(0.65)$ & $1.35(0.62)$ & 0.47 \\
\hline Brain condition within 6 months of age (\%) & & & $<0.001$ \\
\hline Negative & $45(41.6)$ & 312 & \\
\hline IVH & $45(41.6)$ & - & \\
\hline HCP or VM & $6(5.5)$ & 6 & \\
\hline WM or PVL & $12(11.1)$ & - & \\
\hline Others (HCC, microcephaly) & $6(5.5)$ & - & \\
\hline Neurodevelopmental disabilities (\%) & & & $<0.001$ \\
\hline Epilepsy & $12(11.1)$ & $15(4.71)$ & \\
\hline ASD & $15(13.8)$ & $3(0.94)$ & \\
\hline ADHD & $30(27.7)$ & $18(5.66)$ & \\
\hline
\end{tabular}

BBW, Birth body weight; GA, Gestational age; HCC, hypogenesis of the corpus callosum; HCP, Hydrocephalus; IVH, Intraventricular hemorrhage; mins, minutes; PVL, Periventricular leukomalacia; VM, ventriculomegaly; WM, White matter damage; yrs, years, ${ }^{*} t$-test.

\section{Statistical Analysis}

Categorical variables between groups were analyzed using $\chi 2$ tests. Furthermore, we calculated the incidence density rates of epilepsy, ADHD and ASD in both groups (which were subdivided into different age intervals and subdivided by number of FSs). 
In addition to term and preterm, other confounders, such as sex, gestational age, birth body weight, first FS duration and onset age, brain condition within 6 months of age and number of FSs were analyzed and controlled by propensity matching and stratification in the process of logistic regression model [17]. However, the approach of analysis of covariance is a statistical linear model with a continuous outcome variable and two or more predictor variables where at least one is continuous and at least one is categorical, which is not applicable in this analysis. We used two sample t-tests for gestational age and birth body weight, first FS duration and onset age, number of FSs and chi-square tests for sex, urbanization, brain condition within 6 months of age and parent occupation to compare the difference between FS+/preterm+ and FS+/preterm - cohorts (Table 1). Using a logistic regression, we estimated the odds ratios (ORs) and $95 \%$ confidence intervals (CIs) of epilepsy, ADHD and ASD in the FS+/preterm+ group relative to the FS+/pretermgroup. All statistical analyses were performed using PASW Statistics version 18.0 (SPSS Inc., Chicago, IL, United States). In addition, for all statistical analyses executed, we considered the two-tailed $p<0.05$ to be statistically significant.

\section{Results}

\section{Data Analysis}

In total, 426 children who had been diagnosed with FS between 1 January 2005 and 31 December 2013 were enrolled into this study. Table 1 presents the participants demographic factors. The participants mean age was 2.3 years (standard deviation $=1.14$ ) in FS+/preterm+ group and 2.19 years (standard deviation $=1.10$ ) in FS+/preterm - group. The proportion of boys was higher than that of girls in both groups. Related brain imaging abnormalities in the study group were classified as negative $(n=45,41.6 \%)$, intraventricular hemorrhage $(n=45,41.6 \%)$, hydrocephalus or ventriculomegaly $(n=6,5.5 \%)$, white matter damage or periventricular leukomalacia $(n=12,11.1 \%)$ and others $(n=6,5.5 \%)$. Figure 2 illustrates the NDDs associated with children with FS according to their incidence rates.

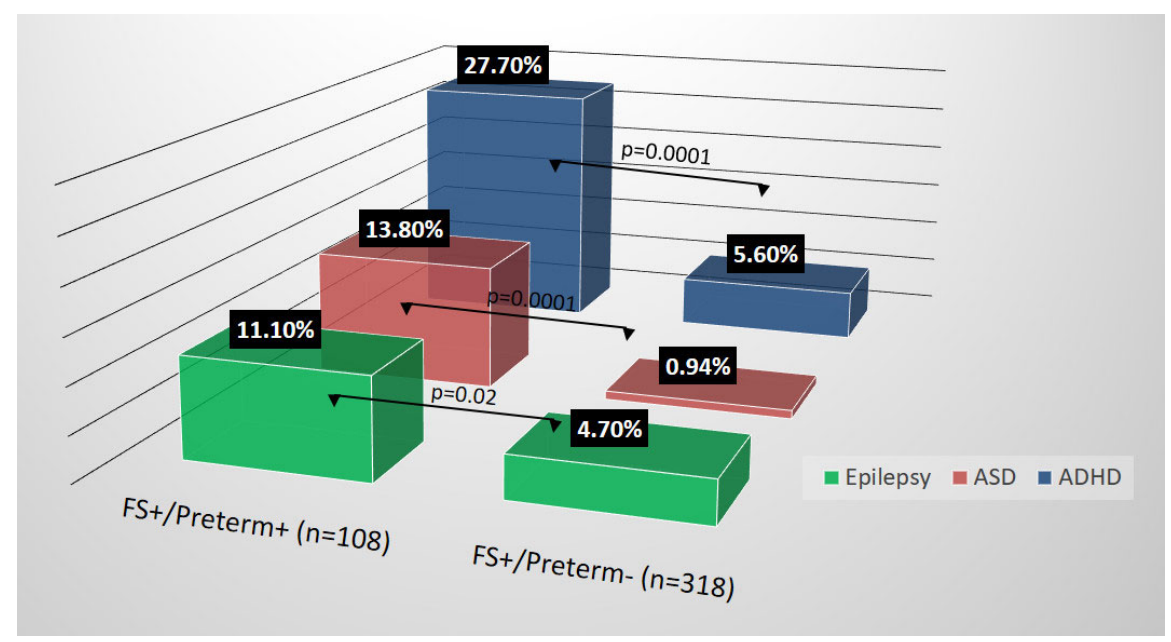

Figure 2. Incidence rates of epilepsy, autism spectrum disorders (ASD) and attention deficit hyperactivity disorder (ADHD) associated with children with febrile seizure in this study.

Table 2 compares the FS+/preterm+ and FS+/preterm - groups in terms of their incidence rates and relative risks of epilepsy, ADHD and ASD. The overall epilepsy risk in the $\mathrm{FS}+$ / preterm + group was higher than that in the FS+/preterm - group (OR, 2.52; 95\% CI, $1.14-5.58 ; p=0.02)$. The overall risk of ADHD in the FS+/preterm+ group was higher than that in the FS+/preterm - group (OR, 6.41; 95\% CI, 3.39-12.09; $p=0.0001)$. Furthermore, the risk of ADHD among patients in the FS+/preterm + group who experienced FS without recurrence (OR, 17.5, 95\% CI, 6.95-44.0; $p=0.0001)$ and whose age of FS onset ranged between 1 and 5 years were even higher than those in the FS+/preterm - group (OR, 7.88; $95 \%$ CI, 3.70-16.7; $p=0.0001$ ). 
Table 2. Incidence Rates and Odds Ratio of Epilepsy, Autism Spectrum Disorder and Attention Deficit Hyperactivity Disorder for the FS+/Preterm - and FS+/Preterm+ Groups and Those Stratified by Age and Number of Febrile Seizures Using a Logistic Regression Model.

\begin{tabular}{|c|c|c|c|c|c|c|c|c|c|}
\hline \multirow[b]{2}{*}{ Group } & \multicolumn{3}{|c|}{ Epilepsy } & \multicolumn{3}{|c|}{ ADHD } & \multicolumn{3}{|c|}{ ASD } \\
\hline & $\begin{array}{l}\text { Event } \\
\text { (No.) }\end{array}$ & $\begin{array}{c}\text { IR } \\
(\%, N)\end{array}$ & OR $(95 \%$ CI $)$ & $\begin{array}{l}\text { Event } \\
\text { (No.) }\end{array}$ & $\begin{array}{c}\text { IR } \\
(\%, N)\end{array}$ & OR $(95 \% \mathrm{CI})$ & $\begin{array}{l}\text { Event } \\
\text { (No.) }\end{array}$ & $\begin{array}{c}\text { IR } \\
(\%, N)\end{array}$ & OR (95\% CI) \\
\hline $\begin{array}{c}\text { Term children } \\
\text { with FS }(N=318)\end{array}$ & 15 & 4.71 & Reference & 18 & 5.66 & Reference & 3 & 0.94 & Reference \\
\hline \multicolumn{10}{|l|}{ Age $(y r s, n)$} \\
\hline $0-1(93)$ & 3 & 0.94 & Reference & 6 & 1.88 & Reference & 1 & 0.31 & Reference \\
\hline $1-5(225)$ & 12 & 3.77 & Reference & 12 & 3.77 & Reference & 2 & 0.62 & Reference \\
\hline \multicolumn{10}{|l|}{ No of FS } \\
\hline $1(225)$ & 0 & 0 & - & 15 & 4.71 & Reference & 1 & 0.31 & Reference \\
\hline$>1(93)$ & 15 & 4.71 & Reference & 3 & 0.94 & Reference & 2 & 0.62 & Reference \\
\hline $\begin{array}{l}\text { Preterm children } \\
\text { with FS }(N=108)\end{array}$ & 12 & 11.1 & $2.52(1.14,5.58)$ * & 30 & 27 & $6.41(3.39,12.09)^{* * *}$ & 15 & 13.9 & $16.9(4.79,59.7)^{* * *}$ \\
\hline \multicolumn{10}{|l|}{ Age $(y r s, n)$} \\
\hline $0-1(30)$ & 3 & 2.77 & $3.33(0.63,17.4)$ & 6 & 5.54 & $3.62(1.07,12.2)$ * & 3 & 2.77 & $10.22(1.02,102.3)$ * \\
\hline $1-5(78)$ & 9 & 8.33 & $2.31(0.93,5.72)$ & 24 & 22.2 & $7.88(3.70,16.7) * * *$ & 12 & 11.1 & $20.27(4.4,92.8) * * *$ \\
\hline \multicolumn{10}{|l|}{ No of FS } \\
\hline $1(27)$ & 3 & 2.77 & - & 15 & 13.9 & $17.5(6.95,44.0)^{* * *}$ & 6 & 5.55 & $64.0(7.35,557) * * *$ \\
\hline$>1(81)$ & 9 & 8.33 & $0.65(0.26,1.57)$ & 15 & 13.9 & $6.81(1.89,24.5) * *$ & 9 & 8.33 & $5.68(1.19,27.1) *$ \\
\hline
\end{tabular}

IR, Incidence rate; OR, Odds ratio; CI, Confidence interval; ASD, Autism spectrum disorder; ADHD, Attention Deficit Hyperactivity Disorder, ${ }^{*} p<0.05,{ }^{* *} p<0.01,{ }^{* * *} p<0.001$.

In addition, children in the FS+/preterm+ group had 16.9 times (95\% CI, 4.79-59.7; $p=0.0001$ ) higher odds of having ASD compared with those in the FS+/preterm - group, which was the same in each stratification subgroup. Among other things, patients in the FS+ / preterm + group who had experienced one episode of FS and whose age at FS onset was greater than 1 year had an even higher risk of ASD than those in the FS+/pretermgroup (OR, 64.0, 95\% CI, 7.35-557, $p=0.0001$; OR, 20.27, 95\% CI, 4.4-92.8; $p=0.0001$ )

Table 3 further compares the possible confounders in children within the FS+/preterm + group for the development of ADHD and ASD. No significant differences were found in terms of sex, gestational age, brain condition, number of FSs, first FS duration and whether the children were small for their gestational age.

Table 3. Odds Ratio of Autism Spectrum Disorder and Attention Deficit Hyperactivity Disorder for FS+/Preterm+ Children with Different Classifications and Their Baseline.

\begin{tabular}{|c|c|c|c|c|}
\hline \multirow{2}{*}{$\mathrm{FS}+/$ Preterm $+(n=108)$} & \multicolumn{2}{|c|}{ ASD } & \multicolumn{2}{|c|}{ ADHD } \\
\hline & OR $(95 \%$ CI $)$ & $p$ & OR $(95 \%$ CI) & $p$ \\
\hline \multicolumn{5}{|l|}{$\operatorname{Sex}{ }^{\dagger}$} \\
\hline $\mathrm{F}$ & 0 & 0.99 & $2.50(0.43,14.23)$ & 0.30 \\
\hline \multicolumn{5}{|l|}{ GA (wks) ${ }^{\dagger}$} \\
\hline 30-35 & $1.11(0.07,15.5)$ & 0.9 & $0.37(0.04,2.99)$ & 0.35 \\
\hline$<30$ & $0.58(0.04,7.91)$ & 0.68 & $0.26(0.03,1.86)$ & 0.18 \\
\hline Brain condition ${ }^{\dagger}$ & & & & \\
\hline Abnormal & $1.14(0.16,7.89)$ & 0.88 & $0.67(0.15,2.91)$ & 0.59 \\
\hline $\begin{array}{c}\text { No. of FS } \\
>1\end{array}$ & $3.15(0.45,21.94)$ & 0.24 & $2.25(0.5,10.01)$ & 0.28 \\
\hline$\underbrace{1 \text { st FS duration (mins) }}_{>10}$ & $1.04(0.09,11.09)$ & 0.97 & $0.37(0.03,3.54)$ & 0.38 \\
\hline $\begin{array}{l}\text { SGA } \\
\text { Yes }\end{array}$ & 0 & 0.99 & $2.35(0.42,13.18)$ & 0.33 \\
\hline
\end{tabular}

FS: febrile seizure; GA: gestational age; SGA: Small for gestational age; wks: weeks. $\emptyset$ Reference for sex (male), GA (35-37 weeks); brain condition at birth (normal); number of FSs (1); first FS duration (1-10 min); SGA (No). 


\section{Discussion}

Significant prognostic markers for subsequent epilepsy in FS were confirmed, including a family history of epilepsy, complex FS, focal FS, short fever duration before seizure, late onset of FS (age > 5 years) and multiple FS recurrences. Multiple FSs increased the risk of epilepsy [18]. Neurological sequelae, including new neurological deficits, intellectual impairment and behavioral disorders, are rare following FS. Studies have speculated a possible link between FS and ASD or other NDDs in children; however, they have lacked relevant predictors $[10,12,13]$. In this study, we attempted to indicate a possible linkage between FS and other NDDs as well as highlight that preterm labor may be a risk factor in the development of epilepsy as well as ASD and ADHD. Through this retrospective study, we demonstrated that preterm children with FS had a significantly increased incidence rate of subsequent epilepsy, ADHD and ASD compared with full-term children with FS. Furthermore, our results showed that the trend of preterm birth acting as a risk factor for FS to the development of ASD and ADHD is much more evident than that of epilepsy.

Although not the main purpose of this study, our results revealed that $11.10 \%$ of preterm patients with FS developed epilepsy, whereas $4.7 \%$ of full-term patients with FS developed epilepsy, both of which were higher than figures previously reported in the literature. Moreover, we found that preterm birth might be a risk factor in combination with FS for the development of childhood epilepsy. However, there was no statistical significance in which we stratified according to the onset age and recurrence of FS. We believe that the formation of epilepsy is much more complicated and so individual risk factors selected in the present study cannot exist independently, that is, there is an interaction between various potential risk factors [18-20]. As we know, children with simple FS exhibit an increased association with the development of epilepsy [21] and a slightly higher risk of subsequent epilepsy (approximately 1\%), compared with that in the general population (approximately $0.5 \%$ ) [22]. The risk of future epilepsy in children with complex FS is approximately $4-6 \%$ depending on the number of complex features [22]. However, we did not differentiate between simple and complex FS in our study because parent descriptions of children's seizures documented in medical records were mostly unreliable. Hence, further research is required to identify whether preterm birth poses a higher risk than complex FS in the development of epilepsy or other NDDs.

Studies have noted the relationship between FSs and ADHD, with some reporting FS to be a risk factor for subsequent ADHD $[10,12,13]$. Ku et al. reported that FS increases the risk of subsequent ADHD in areas with high levels of urbanization, as well as that recurrent FS increased the cumulative incidence of ADHD [12]. Salehi et al. demonstrated that hyperactivity had a significant relationship with FS among male patients [23]. However, whether FSs increase the risk of ADHD is a long issue of debate since conventional concepts believed simple FS had little effect on the adverse effects between behavior, academic performance and neurocognitive attention. Interestingly, only a few studies mentioned on the potential risk factors, such as age of the 1st FS onset, recurrence of FS, prematurity or not and so on $[13,24]$. On the other hand, despite years of controversy regarding the relationship between ASD and epilepsy, no definite consensus has been reached to establish the nature of the relationship [25]. Some population-based studies have identified a bidirectional relationship in which not only patients with epilepsy are at increased risk of suffering from certain neurological and psychiatric disorders (e.g., ASD, depression, anxiety disorders, ADHD and psychosis), but also patients with such conditions are at increased risk of epilepsy [26]. Other studies have suggested shared mechanisms between epilepsy and ASD [27-29]. Gillberg et al., conducted a leading study regarding FS and its association with ASD [10]. Following Gillberg et al., our present study further identified higher incidence rates of ADHD and ASD in preterm children with FS.

Our results, on the contrary, revealed some differences than before. After taking gestational age into account, we found that FS onset above 1 year of age might significantly increase the risk of ASD and ADHD, but the puzzling thing is that children without recurrence of FS had an even higher risk of developing ASD and ADHD. The above 
phenomenon did not appear when considering epilepsy. Although we have obtained new findings from our observational data, there is no reasonable explanations for them yet. Therefore, further studies to determine the role of prematurity in the development of ADHD and ASD across the different stages of the developing brain will be essential to elucidate our findings [30,31].

Preterm birth is the leading cause of neurobehavioral impairment and disability, causing a large economic burden [32,33]. Studies have found a higher prevalence of prematurity in children with ADHD or ASD, as well as that preterm birth increased the risk of subsequent ADHD or ASD [16,34-37]. The shorter the gestation age of those infants, the higher their risk of ASD [37]. However, when we compared the possible confounders within the FS+/preterm+ group in terms of the development of ADHD and ASD, we did not notice any significant difference between them (Table 3). Such a result was incongruous with previous findings [35,37]; thus, future studies may employ larger study samples and more in-depth study designs.

Pathophysiologically speaking, myelination processes and brain development are interrupted in prematurely born children and the connectivity between brain regions could be disrupted as well; this may explain the occurrence of NDDs and the emotional/behavioral problems in this population [38]. Despite the benign nature of FS, a genetic predisposition to the condition has been recognized; studies have disclosed that genetic variants in loci containing sodium channel genes (e.g., SCN1A and SCN1B among others) [39], could impede human brain development and are probably related not only to childhood epilepsy, but also to intellectual disability and ASD [40-42]. In other words, there might be a genetic variant that predisposes children to febrile seizures or epilepsy with febrile seizures and is also associated with abnormal brain development and subsequent epilepsy, intellectual disability and ASD $[43,44]$. Thus, we believe that preterm children with repeated FSs are at risk of epilepsy and NDDs and more studies are necessary to determine whether there is the same genetic variant between them.

This study had some limitations. First, some confounding factors may have affected the results, such as the mother's medical condition during pregnancy, socioeconomic status, pharmacological treatment of children with preterm birth, malnutrition and environmental factors. Second, our sample size was relatively small and thus a population-based cohort study should be designed to prove our findings. Third, we did not perform an analysis of seizure semiology because of restrictions on the study design. Fourth, preterm children are monitored much more closely for developmental delay and therefore are more likely to be diagnosed having ASD or ADHD.

A large prospective cohort longitudinal study that investigates whether the incidence rates of ASD and ADHD are significantly different between preterm and control groups may help to confirm our findings. Furthermore, additional research that focuses on neuroimaging, genetic susceptibility, iron homeostasis, or proinflammatory cytokines may identify potential mechanisms.

\section{Conclusions}

This study investigated whether preterm birth is a risk factor for subsequent epilepsy, ASD and ADHD in children with FS. It is crucial for pediatricians to identify the early symptoms of ADHD or ASD in children with a history of FS - especially those born prematurely - to initiate proper assessment and treatment. Additional patient data and more in-depth studies are warranted to elicit potential cofounders to clarify the influence of preterm labor on FS and its association with ADHD and ASD.

Author Contributions: S.-Y.H. collected the data, analyzed the data and prepared the initial draft of the manuscript. C.-H.L., I.-C.C., W.-D.L. and I.-C.L. took part in designing the study and wrote the final draft of the manuscript. The statistics for the study were compiled by C.-H.L., W.-D.L. and I.-C.C., who also took part in the editing process and the revision of the tables. All authors have read and agreed to the published version of the manuscript. 
Funding: This research received no external funding.

Institutional Review Board Statement: After a full description of the study, written informed consent of participation was obtained from the legal guardians. The study protocol was approved by the Ethics Review Board of the China Medical University ethics committee (Approval \# CMUH108REC1-023).

Informed Consent Statement: Not applicable. Because the study was based on medical record review and all individuals' information were not appeared in the study.

Data Availability Statement: Datasets are available on request.

Acknowledgments: We would like to thank the Genetic Medicine Laboratory of China Medical University Hospital, Ministry of Science and Technology of ROC (MOST 107-2314-B-039-003) and China Medical University Hospital Medical Research Department (DMR-110-245) for giving support and assistance to this work.

Conflicts of Interest: The authors declare no conflict of interest.

\section{Abbreviations}

$\begin{array}{ll}\text { ADHD } & \text { Attention Deficit Hyperactivity Disorder } \\ \text { ASD } & \text { Autism Spectrum Disorder } \\ \text { CI } & \text { Confidence Interval } \\ \text { DSM } & \text { Diagnostic and Statistical Manual of Mental Disorders } \\ \text { FS } & \text { Febrile Seizure } \\ \text { MR } & \text { Mental Retardation } \\ \text { NDDs } & \text { Neurodevelopmental Disorders } \\ \text { OR } & \text { Odds Ratio } \\ \text { TS } & \text { Tourette Syndrome }\end{array}$

\section{References}

1. Lung, F.-W.; Chiang, T.-L.; Lin, S.-J.; Lee, M.-C.; Shu, B.-C. Advanced Maternal Age and Maternal Education Disparity in Children with Autism Spectrum Disorder. Matern. Child. Health J. 2018, 22, 941-949. [CrossRef]

2. Janecka, M.; Hansen, S.N.; Modabbernia, A.; Browne, H.A.; Buxbaum, J.; Schendel, D.E.; Reichenberg, A.; Parner, E.; Grice, D.E. Parental Age and Differential Estimates of Risk for Neuropsychiatric Disorders: Findings from the Danish Birth Cohort. J. Am. Acad. Child. Adolesc. Psychiatry 2019, 58, 618-627. [CrossRef] [PubMed]

3. Russell, A.E.; Ford, T.; Williams, R.; Russell, G. The Association Between Socioeconomic Disadvantage and Attention Deficit/Hyperactivity Disorder (ADHD): A Systematic Review. Child. Psychiatry Hum. Dev. 2015, 47, 440-458. [CrossRef] [PubMed]

4. Durkin, M.S.; Yeargin-Allsopp, M. Socioeconomic Status and Pediatric Neurologic Disorders: Current Evidence. Semin. Pediatr. Neurol. 2018, 27, 16-25. [CrossRef] [PubMed]

5. Huang, L.; Wang, Y.; Zhang, L.; Zheng, Z.; Zhu, T.; Qu, Y.; Mu, D. Maternal Smoking and Attention-Deficit/Hyperactivity Disorder in Offspring: A Meta-analysis. Pediatrics 2017, 141, e20172465. [CrossRef] [PubMed]

6. Jung, Y.; Lee, A.M.; McKee, S.A.; Picciotto, M.R. Maternal smoking and autism spectrum disorder: Meta-analysis with population smoking metrics as moderators. Sci. Rep. 2017, 7, 1-10. [CrossRef]

7. Hagan, J.F.; Balachova, T.; Bertrand, J.; Chasnoff, I.; Dang, E.; Fernandez-Baca, D.; Kable, J.; Kosofsky, B.; Senturias, Y.N.; Singh, N.; et al. Neurobehavioral Disorder Associated with Prenatal Alcohol Exposure. Pediatrics 2016, 138, e20151553. [CrossRef]

8. Vestergaard, M.; Pedersen, M.G.; Østergaard, J.R.; Pedersen, C.B.; Olsen, J.; Christensen, J. Death in children with febrile seizures: A population-based cohort study. Lancet 2008, 372, 457-463. [CrossRef]

9. Vestergaard, M.; Pedersen, C.B.; Sidenius, P.; Olsen, J.; Christensen, J. The Long-Term Risk of Epilepsy after Febrile Seizures in Susceptible Subgroups. Am. J. Epidemiol. 2007, 165, 911-918. [CrossRef]

10. Gillberg, C.; Lundström, S.; Fernell, E.; Nilsson, G.; Neville, B. Febrile Seizures and Epilepsy: Association with Autism and Other Neurodevelopmental Disorders in the Child and Adolescent Twin Study in Sweden. Pediatr. Neurol. 2017, 74, 80-86.e2. [CrossRef]

11. Baumann, R.J.; Duffner, P.K. Treatment of children with simple febrile seizures: The aap practice parameter. Pediatr. Neurol. 2000, 23, 11-17. [CrossRef]

12. Ku, Y.-C.; Muo, C.-H.; Ku, C.-S.; Chen, C.-H.; Lee, W.-Y.; Shen, E.-Y.; Chang, Y.-J.; Kao, C.-H. Risk of subsequent attention deficit-hyperactivity disorder in children with febrile seizures. Arch. Dis. Child. 2013, 99, 322-326. [CrossRef] [PubMed]

13. Bertelsen, E.N.; Larsen, J.T.; Petersen, L.V.; Christensen, J.; Dalsgaard, S. Childhood Epilepsy, Febrile Seizures, and Subsequent Risk of ADHD. Pediatrics 2016, 138, e20154654. [CrossRef] [PubMed] 
14. Jarjour, I.T. Neurodevelopmental Outcome After Extreme Prematurity: A Review of the Literature. Pediatr. Neurol. 2015, 52, 143-152. [CrossRef] [PubMed]

15. Ask, H.; Gustavson, K.; Ystrom, E.; Havdahl, A.; Tesli, M.; Askeland, R.B.; Reichborn-Kjennerud, T. Association of Gestational Age at Birth with Symptoms of Attention-Deficit/Hyperactivity Disorder in Children. JAMA Pediatr. 2018, 172, 749-756. [CrossRef]

16. Sucksdorff, M.; Lehtonen, L.; Chudal, R.; Suominen, A.; Joelsson, P.; Gissler, M.; Sourander, A. Preterm Birth and Poor Fetal Growth as Risk Factors of Attention-Deficit/Hyperactivity Disorder. Pediatrics 2015, 136, e599-e608. [CrossRef]

17. Pourhoseingholi, M.A.; Baghestani, A.; Vahedi, M. How to control confounding effects by statistical analysis. Gastroenterol. Hepatol. Bed Bench 2012, 5, 79-83. [PubMed]

18. Pavlidou, E.; Panteliadis, C. Prognostic factors for subsequent epilepsy in children with febrile seizures. Epilepsia 2013, 54, 2101-2107. [CrossRef] [PubMed]

19. Dreier, J.W.; Li, J.; Sun, Y.; Christensen, J. Evaluation of Long-term Risk of Epilepsy, Psychiatric Disorders, and Mortality Among Children with Recurrent Febrile Seizures. JAMA Pediatr. 2019, 173, 1164-1170. [CrossRef]

20. Gencpinar, P.; Yavuz, H.; Bozkurt, Ö.; Haspolat, Ş.; Duman, Ö. The risk of subsequent epilepsy in children with febrile seizure after 5 years of age. Seizure 2017, 53, 62-65. [CrossRef]

21. Chiang, L.-M.; Huang, G.-S.; Sun, C.-C.; Hsiao, Y.-L.; Hui, C.K.; Hu, M.-H. Association of developing childhood epilepsy subsequent to febrile seizure: A population-based cohort study. Brain Dev. 2018, 40, 775-780. [CrossRef] [PubMed]

22. Leung, A.K.; Hon, K.L.; Leung, T.N. Febrile seizures: An overview. Drugs Context 2018, 7, 1-12. [CrossRef] [PubMed]

23. Salehi, B.; Yousefichaijan, P.; Arian, S.S.; Ebrahimi, S.; Naziri, M. Comparison of Relation between Attention Deficit Hyperactivity Disorder in Children with and without Simple Febrile Seizure Admitted in Arak Central Iran. Iran. J. Child Neurol. 2016, 10, 56-61.

24. Chang, Y.-C.; Guo, N.-W.; Huang, C.-C.; Wang, S.-T.; Tsai, J.-J. Neurocognitive attention and behavior outcome of school-age children with a history of febrile convulsions: A population study. Epilepsia 2000, 41, 412-420. [CrossRef] [PubMed]

25. Besag, F.M. Current controversies in the relationships between autism and epilepsy. Epilepsy Behav. 2015, 47, 143-146. [CrossRef]

26. Kanner, A.M.; Scharfman, H.; Jette, N.; Anagnostou, E.; Bernard, C.; Camfield, C.; Camfield, P.; Legg, K.; Dinstein, I.; Giacobbe, P.; et al. Epilepsy as a Network Disorder (1): What can we learn from other network disorders such as autistic spectrum disorder and mood disorders? Epilepsy Behav. 2017, 77, 106-113. [CrossRef]

27. Richard, A.E.; Scheffer, I.E.; Wilson, S.J. Features of the broader autism phenotype in people with epilepsy support shared mechanisms between epilepsy and autism spectrum disorder. Neurosci. Biobehav. Rev. 2017, 75, 203-233. [CrossRef]

28. Keller, R.; Basta, R.; Salerno, L.; Elia, M. Autism, epilepsy, and synaptopathies: A not rare association. Neurol. Sci. 2017, 38, 1353-1361. [CrossRef]

29. McCue, L.M.; Flick, L.H.; Twyman, K.A.; Xian, H.; Conturo, T.E. Prevalence of non-febrile seizures in children with idiopathic autism spectrum disorder and their unaffected siblings: A retrospective cohort study. BMC Neurol. 2016, 16, 1-9. [CrossRef]

30. Peralta-Carcelen, M.; Schwartz, J.; Carcelen, A.C. Behavioral and Socioemotional Development in Preterm Children. Clin. Perinatol. 2018, 45, 529-546. [CrossRef]

31. Arora, N.K.; Nair, M.K.C.; Gulati, S.; Deshmukh, V.; Mohapatra, A.; Mishra, D.; Patel, V.; Pandey, R.M.; Das, B.C.; Divan, G.; et al. Neurodevelopmental disorders in children aged 2-9 years: Population-based burden estimates across five regions in India. PLoS Med. 2018, 15, e1002615. [CrossRef] [PubMed]

32. El-Dib, M.; Massaro, A.N.; Glass, P.; Aly, H. Neurodevelopmental assessment of the newborn: An opportunity for prediction of outcome. Brain Dev. 2011, 33, 95-105. [CrossRef] [PubMed]

33. Vieira, M.E.B.; Linhares, M.B.M. Developmental outcomes and quality of life in children born preterm at preschool- and school-age. J. Pediatr. 2011, 87, 281-291. [CrossRef]

34. Rogers, C.E.; Lean, R.E.; Wheelock, M.D.; Smyser, C.D. Aberrant structural and functional connectivity and neurodevelopmental impairment in preterm children. J. Neurodev. Disord. 2018, 10, 38. [CrossRef] [PubMed]

35. Moster, D.; Lie, R.T.; Markestad, T. Long-Term Medical and Social Consequences of Preterm Birth. N. Engl. J. Med. 2008, 359, 262-273. [CrossRef]

36. Fezer, G.F.; Matos, M.B.; Nau, A.L.; Zeigelboim, B.S.; Marques, J.M.; Liberalesso, P.B.N. Perinatal Features of Children with Autism Spectrum Disorder. Rev. Paul. Pediatr. 2017, 35, 2. [CrossRef]

37. Kuzniewicz, M.W.; Wi, S.; Qian, Y.; Walsh, E.M.; Armstrong, M.A.; Croen, L.A. Prevalence and Neonatal Factors Associated with Autism Spectrum Disorders in Preterm Infants. J. Pediatr. 2014, 164, 20-25. [CrossRef]

38. Lubsen, J.; Vohr, B.; Myers, E.; Hampson, M.; Lacadie, C.; Schneider, K.C.; Katz, K.H.; Constable, R.; Ment, L.R. Microstructural and Functional Connectivity in the Developing Preterm Brain. Semin. Perinatol. 2011, 35, 34-43. [CrossRef] [PubMed]

39. Feenstra, B.; Pasternak, B.; Geller, F.; Carstensen, L.; Wang, T.-F.; Huang, H.; Eitson, J.L.; Hollegaard, M.V.; Svanström, H.; Vestergaard, M. Common variants associated with general and MMR vaccine-related febrile seizures. Nat. Genet. 2014, 46, 1274-1282. [CrossRef]

40. Fry, A.E.; Rees, E.; Thompson, R.; Mantripragada, K.; Blake, P.; Jones, G.; Morgan, S.; Jose, S.; Mugalaasi, H.; Archer, H.; et al. Pathogenic copy number variants and SCN1A mutations in patients with intellectual disability and childhood-onset epilepsy. BMC Med. Genet. 2016, 17, 1-9. [CrossRef]

41. Papp-Hertelendi, R.; Tényi, T.; Hadzsiev, K.; Hau, L.; Benyus, Z.; Csábi, G. First report on the association of SCN1A mutation, childhood schizophrenia and autism spectrum disorder without epilepsy. Psychiatry Res. 2018, 270, 1175-1176. [CrossRef] [PubMed] 
42. Rubinstein, M.; Patowary, A.; Stanaway, I.B.; McCord, E.; Nesbitt, R.R.; Archer, M.; Scheuer, T.; Nickerson, D.; Raskind, W.H.; Wijsman, E.M.; et al. Association of rare missense variants in the second intracellular loop of NaV1.7 sodium channels with familial autism. Mol. Psychiatry 2016, 23, 231-239. [CrossRef]

43. Tang, L.; Lu, X.; Tao, Y.; Zheng, J.; Zhao, P.; Li, K.; Li, L. SCN1A rs3812718 polymorphism and susceptibility to epilepsy with febrile seizures: A meta-analysis. Gene 2014, 533, 26-31. [CrossRef] [PubMed]

44. Audenaert, D.; Claes, L.; Ceulemans, B.; Lofgren, A.; Van Broeckhoven, C.; De Jonghe, P. A deletion in SCN1B is associated with febrile seizures and early-onset absence epilepsy. Neurology 2003, 61, 854-856. [CrossRef] [PubMed] 